Article

\title{
Characteristics of Smoldering on Moist Rice Husk for Silica Production
}

\author{
Shengtai Yan ${ }^{1}$, Dezheng Yin ${ }^{1}$, Fang He ${ }^{1, *}$, Junmeng Cai ${ }^{2}$, Thomas Schliermann ${ }^{3}$ and Frank Behrendt ${ }^{1,4}$ \\ 1 School of Transportation and Vehicle Engineering, Shandong University of Technology, Zibo 255049, China; \\ Shengtai_Yan@163.com (S.Y.); ydz2332398336@163.com (D.Y.); frank.behrendt@tu-berlin.de (F.B.) \\ 2 School of Agriculture and Biology, Shanghai Jiao Tong University, Shanghai 200240, China; jmcai@sjtu.edu.cn \\ 3 DBFZ Deutsches Biomasseforschungszentrum Gemeinnützige GmbH, 04347 Leipzig, Germany; \\ thomas.schliermann@dbfz.de \\ 4 Institute of Energy Engineering, Technische Universität Berlin, 10623 Berlin, Germany \\ * Correspondence: fanghe916@daad-alumni.de
}

check for updates

Citation: Yan, S.; Yin, D.; He, F.; Cai, J.; Schliermann, T.; Behrendt, F. Characteristics of Smoldering on Moist Rice Husk for Silica Production. Sustainability 2022, 14, 317. https:// doi.org/10.3390/su14010317

Academic Editor:

Alberto-Jesus Perea-Moreno

Received: 2 December 2021

Accepted: 24 December 2021

Published: 29 December 2021

Publisher's Note: MDPI stays neutral with regard to jurisdictional claims in published maps and institutional affiliations.

Copyright: (C) 2021 by the authors. Licensee MDPI, Basel, Switzerland. This article is an open access article distributed under the terms and conditions of the Creative Commons Attribution (CC BY) license (https:// creativecommons.org/licenses/by/ $4.0 /)$.

\begin{abstract}
In order to assess the possibility of silica production via smoldering of moist rice husk, experiments of washed (moist) rice husk ( $7 \mathrm{~kg}$ with moisture content of $51 \%)$ in a newly designed smoldering apparatus was performed. The temperature inside the fuel bed during smoldering was recorded, and characteristics of ash were analyzed. Results showed that the highest temperature in the middle of the naturally piled fuel bed was about $560.0^{\circ} \mathrm{C}$, lower than those in most of combustors. Some volatiles from the lower part of the fuel bed adhere to its upper ash during piled smoldering. Silica content and specific surface area of ash from smoldering of washed (moist) rice husk were $86.4 \%$ and $84.9 \mathrm{~m}^{2} / \mathrm{g}$, respectively. Compared to our experiments, they are close to smoldering of unwashed rice husk $\left(89.0 \%, 67.7 \mathrm{~m}^{2} / \mathrm{g}\right)$; different from muffle furnace burning $\left(600{ }^{\circ} \mathrm{C}, 2 \mathrm{~h}\right)$ of washed $\left(93.4 \%, 164.9 \mathrm{~m}^{2} / \mathrm{g}\right)$ and un-washed $\left(90.2 \%, 45.7 \mathrm{~m}^{2} / \mathrm{g}\right)$ rice husk. The specific surface area is higher than those from most industrial methods (from 11.4 to $39.3 \mathrm{~m}^{2} / \mathrm{g}$ ). After some improvements, the smoldering process has great potential in mass product of high quality silica directly from moist rice husk.
\end{abstract}

Keywords: smoldering; rice husk; high moisture content; silica; specific surface area

\section{Introduction}

Smoldering is slow, low-temperature, and flameless burning of porous fuels, which is an important and complex phenomenon [1,2]. The application of it in the field of waste-to-energy conversion such as sludge treatment [3], recovery of resources from waste streams [4], and biomass energy conversion [5] has attracted lots of attention in recent years. The main advantages are its low temperature of the solid phase [6] and self-sustainability in a fuel bed with high moisture content (75-80 wt.\%) [7]. From an environmental point of view, these characteristics avoid the ash-related slagging/corrosion [8], making nutrients recovery easy via recycling of ash directly to farms [9] and reducing the pollution of solid waste. As to energy consumption, it makes the complete burning of moist solid waste possible [10], reducing the energy consumption for drying fuel.

Rice husk is a typical biomass waste [11], accounting for 14-25\% of the grain's overall mass [12]. In 2021, approximately 150 million tons of rice husk were produced around the world, with China contributing approximately 40 million tons. Nowadays most rice husk is directly buried or open burned [13] due to its low nutritive value for humans compared with rice grain and rice bran [14]. Direct burying results in soil pollution, because of its slow decomposition owing to its hard surface resulting from its high silicon and high lignin content [15]. Open burning leads to air pollution because of the release of fine dust and incomplete combustion gases of $\mathrm{CO}, \mathrm{NO}_{\mathrm{x}}, \mathrm{CH}_{4}$, poly-cyclic hydrocarbons $(\mathrm{PAH})$ and soot [16]. 
There is great potential in producing silica from rice husk due to its high content of amorphous silica (around 18-23\% [17]) and ash (around 85-95\% [18]). Silica is an important inorganic material and is widely used in various fields such as fertilizer, insulator, adsorbent and catalyst [19]. It is characterized by high mechanical strength, good chemical stability, high-temperature resistance, easy dispersion in solvents, etc [20,21]. With the widespread application of silica, a variety of methods have been adopted to produce it, such as precipitation, plasma synthesis, chemical vapor deposition, micro emulsion processing, combustion synthesis and hydrothermal technique [22,23]. At present, most popular mass producing methods are precipitation from alkaline silicates and hydrothermal treatment of sand with lye [24]. However, both methods are expensive, intensive energy input, and environmentally harmful due to the production of dust, nitrogen and sulfur oxides, etc in the process of obtaining silica $[25,26]$.

Producing silica from thermochemical conversion of rice husk has received considerable attention due to its economic and environmental advantages [27]. As to lab-scale production, Dizaji et al. [28] prepared silica by burning raw rice husk and pretreated rice husk (water washing at $50{ }^{\circ} \mathrm{C}$ for $2 \mathrm{~h}$ ) in a muffle furnace at $600{ }^{\circ} \mathrm{C}$ for $4 \mathrm{~h}$. The specific surface area was around 45.0 and $240.0 \mathrm{~m}^{2} / \mathrm{g}$, respectively. Abu Bakar et al. [29] prepared silica by burning rice husk (unleached/acid-leached) in a muffle furnace $\left(600{ }^{\circ} \mathrm{C}\right.$ for $2 \mathrm{~h}$ ). The purity of silica from unleached and acid-leached rice husk was 95.8 and $99.6 \mathrm{wt} \%$ (XRF results), respectively, and specific surface area was 116.0 and $218.0 \mathrm{~m}^{2} / \mathrm{g}$, respectively. Almeida et al. [30] prepared a mixture of silica and carbon by pyrolysis of raw rice husk in a tubular furnace. The obtained silica was black, in a mixture of amorphous and crystalline, with purity of $81.6 \mathrm{wt} . \%$ and specific surface area of $114.0 \mathrm{~m}^{2} / \mathrm{g}$. Schliermann et al. [31] obtained ashes produced from water washed $\left(50{ }^{\circ} \mathrm{C}\right.$ for $2 \mathrm{~h}$ ) rice husk using ÖKOTHERM ${ }^{\circledR}$ furnaces. The ashes are post-treated with acid and then thermally treated at $650{ }^{\circ} \mathrm{C}$ using a muffle furnace. The specific surface area of silica is about $150-200 \mathrm{~m}^{2} / \mathrm{g}$. As to industrial production, Fernandes et al. [32] investigated characteristics of ash from burning rice husk in a grate furnace, a fluidized bed, and a suspension/entrained combustor. The silica content in these three types of ash was 90.0,96.7, $93.6 \mathrm{wt} . \%$, and the specific surface area was $39.3,11.4,26.7 \mathrm{~m}^{2} / \mathrm{g}$, respectively. The specific surface area of silica from mass production tends to be lower than that prepared in a laboratory, which may be related to none pretreatment of rice husk and the high burning temperature in industrial combustors. It is recorded that high combustion temperature results in the transformation of amorphous silica to crystalline material [33].

Pretreatment of rice husk is an effective way to increase the purity and specific surface area of silica and typical pretreatments for rice husk are acid-leaching and waterwashing [29,34,35]. Moisture content of the treated rice husk is normally high. According to our pre-experiments, moisture content of rice husk is around 50\% after washing. The moist rice husk is not suitable to be burned directly in a normal combustor (the moisture content in a fluidized bed combustor needs to be <35\% [36], for a suspension burner < $15 \%$ [37]). Smoldering might be a good choice for thermochemical conversion of moist rice husk directly to silica. Yet, to the best of our knowledge there are no experiments using smoldering in literature.

The objective of this study is to assess the possibility of silica production via smoldering of rice husk with high moisture content omitting a drying step before thermochemical conversion. A smoldering apparatus was designed and smoldering experiment of rice husk with high moisture content was performed. Temperature inside a fuel bed was recorded and characteristics of ash (silica content, specific surface area and mass loss characteristic) were analyzed.

\section{Materials and Methods}

\subsection{Material}

Rice husk was collected from rural southern China in 2021. Two types of rice husk (washed/unwashed) were chosen as raw material in the experiment. The washing process 
is the following: $3.5 \mathrm{~kg}$ of rice husk was put into a bucket ( $\phi 42 \mathrm{~cm}$ diameter $\times 40 \mathrm{~cm}$ height), then the bucket was filled with tap water (mass ration of water to rice husk: 10:1). The mixture was stirred for $10 \mathrm{~min}$ at ambient temperature. After being immersed for $12 \mathrm{~h}$, rice husk was taken out and leaked above a screen in air for $1 \mathrm{~h}$. The proximate and ultimate analysis of washed and unwashed rice husk were performed three times and the results were shown in Table 1.

Table 1. Proximate and elemental analysis of the rice husk. Oxygen is calculated by difference $(\mathrm{C}+\mathrm{H}+\mathrm{O}+\mathrm{N}+\mathrm{S}+\mathrm{Ash}=100$ wt. $\%$, dry basis $)$.

\begin{tabular}{cccccccccc}
\hline & \multicolumn{3}{c}{ Proximate Analysis (Arrival Basis, wt.\%) } & \multicolumn{4}{c}{ Elemental Analysis (Dry Basis, wt.\%) } \\
\hline & Moisture & Volatile & Ash & Fixed Carbon & C & H & O & N & S \\
\hline Washed & $51.0 \pm 0.2$ & $32.0 \pm 1.5$ & $9.3 \pm 0.3$ & $7.7 \pm 0.8$ & $40.2 \pm 0.3$ & $5.5 \pm 0.1$ & $35.0 \pm 0.2$ & $0.3 \pm 0.1$ & $<0.1$ \\
Unwashed & $8.1 \pm 0.1$ & $59.0 \pm 1.4$ & $18.4 \pm 0.1$ & $14.5 \pm 0.7$ & $38.7 \pm 0.3$ & $5.4 \pm 0.1$ & $35.5 \pm 0.2$ & $0.2 \pm 0.1$ & $<0.1$ \\
\hline
\end{tabular}

\subsection{Experimental Set-Up}

A batch smoldering apparatus consisting of three parts (a smoldering chamber, a gas burning chamber and a heat exchanger) was designed, as shown in Figure 1. The smoldering chamber is rectangular (inner size $60 \times 30 \times 30 \mathrm{~cm}$ ) with an insulation layer $(4 \mathrm{~cm})$ outside of its inner wall. An air inlet $(\phi 5 \mathrm{~cm})$ and a flue gas outlet $(\phi 5 \mathrm{~cm})$ are on the left and the right wall, respectively. A hole $(\phi 30 \mathrm{~cm})$ with door on the top wall is used for material feeding and ash removal. The gas burning chamber is a square cavity $(30 \times 30 \times 30 \mathrm{~cm})$ with an insulation layer $(4 \mathrm{~cm})$ outside of its inner wall. Its inlet $(\phi 5 \mathrm{~cm})$ on the left wall is connected with the flue gas outlet of the smoldering chamber. A quartz glass tube inside the burner is used to introduce the incomplete combustion flue gas from the smoldering chamber to the bottom of the burner, then the gas is ignited using an igniter. The heat exchanger is a cylinder with a diameter of 30 and a height of $100 \mathrm{~cm}$. The heat is transferred from high temperature flue gas through three tubes (diameter of 5 and a height of $40 \mathrm{~cm}$ ) to the water outside them. Rice husk is smoldered in the smoldering chamber, smoke is burned out in the gas burning chamber, and flue gas is discharged into the air after cooled in the heat exchanger.

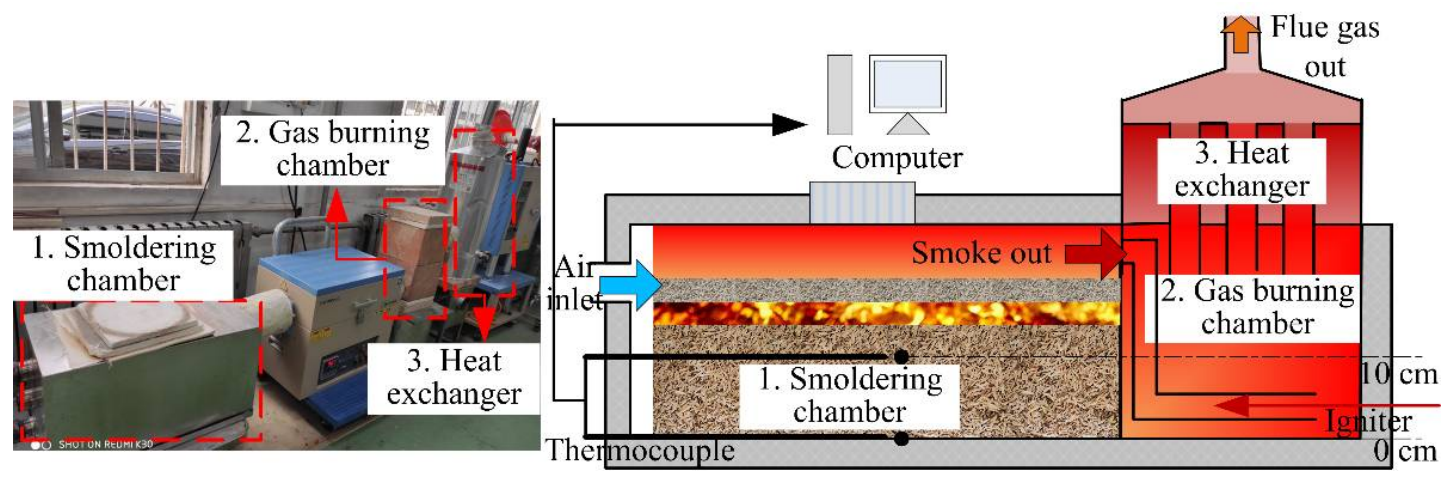

Figure 1. Photo and schematic of the smoldering apparatus.

\subsection{Ash Preparation and Treatment}

\subsubsection{Ash Preparation from Rice Husk}

For comparison, four types of ash-from washed/unwashed rice husk via smoldering and muffle furnace burning - were prepared. The washed and unwashed rice husk ( $3.5 \mathrm{~kg}$ of raw materials) were put naturally piled into the smoldering chamber. The height of the fuel beds was around 24 and $20 \mathrm{~cm}$, and the bulk density were about 160 and $100 \mathrm{~kg} / \mathrm{m}^{3}$, respectively. Then, it was ignited with a block of solid alcohol at the air inlet. Two thermocouples ( $\phi 1 \mathrm{~mm}$, KMTXL-040-G) were put into the bottom and middle $(10 \mathrm{~cm}$ from the bottom) layer of the fuel bed to monitor the change of temperature inside the fuel bed, 
and data were recorded every $60 \mathrm{~s}$. It was found that a thin layer of upper ash was black due to the low temperature and the other part of ash was homogeneous after extinguishing and cooling of the fuel bed. A vacuum cleaner was used to remove the black ash on the upper layer and $200 \mathrm{~g}$ rice husk ash was taken out from the center of the piled residue every time.

About $3 \mathrm{~g}$ of washed and unwashed rice husk were put into an ash tray $(6 \times 3 \times 2 \mathrm{~cm})$ respectively, heated in a muffle furnace from ambient temperature to $600{ }^{\circ} \mathrm{C}$ at $10{ }^{\circ} \mathrm{C} / \mathrm{min}$ and holding for $2 \mathrm{~h}$. Air entered the muffle furnace through a $2-3 \mathrm{~cm}$ gap between the furnace door and the wall. Then the ash was taken out and cooled to ambient temperature in a desiccator for later use.

\subsubsection{Grinding and Drying of Ash}

For homogeneity in the subsequent measurements, the four types of ash were separately crushed to powder with a particle size $<120$ mesh using an agate mortar. After that, these powders were dried in an oven at $105^{\circ} \mathrm{C}$ for $24 \mathrm{~h}$.

\subsection{Thermal and Physical Characterization of Ash}

Mass loss characteristic was analyzed using a simultaneous thermogravimetric analysis (TGA DSC1, Mettler TOLEDO). To avoid corrosion to the instrument, a pair of crucibles (inner: alumina $50 \mu \mathrm{L}$, outer: platinum $70 \mu \mathrm{L}$ ) were used in experiments. About $8 \mathrm{mg}$ of ash was put into the inner crucible and heated from 50 to $950{ }^{\circ} \mathrm{C}$ at a heating rate of $10^{\circ} \mathrm{C} / \mathrm{min}$. An air flow rate of $200 \mathrm{~mL} / \mathrm{min}$ was used as reactive gas and $20 \mathrm{~mL} / \mathrm{min}$ of $\mathrm{N} 2 \mathrm{was}$ used as protective gas. Each experiment was repeated three times to check reproducibility.

The contents of silica and other elements in ash were triplicate and measured by Wavelength Dispersive X-Ray Fluorescence Spectrometer (ZXS100e, Rigaku Corporation) at room temperature. It should be noted that contents are only reliable for elements with atomic weight $\geq 23$ [38]. Because of the data overflow of the results of carbon and boron, the results of them were deleted before calculation of the oxides' content.

Specific surface area was evaluated according to the Brunnauer, Emmett and Teller (BET) method and based on the nitrogen adsorption of the material at $77 \mathrm{~K}$. It was determined in the pressure range of $\mathrm{p} / \mathrm{p}_{0}=0.05-0.3$ [28], where $\mathrm{p}$ is the system pressure, and $\mathrm{p}_{0}$ is the initial pressure ( 1 bar in this experiment). The measurement was conducted in a surface area analyzer (ASAP 2460, Micromeritics).

\section{Results and Discussion}

\subsection{Characteristics of Smoldering Process}

\subsubsection{Temperature inside Fuel Bed}

Temperature inside the washed (moist) and unwashed fuel bed is shown in Figure 2. The temperature history at one spot of the batch fuel bed can be divided into two stages-drying and oxidation. At the drying stage, the temperature first increases and then stabilizes at a temperature of about $60^{\circ} \mathrm{C}$. This is similar to the temperature of smoldering pine bark particle [39] and sewage sludge [4], which is different from the temperature (around $100{ }^{\circ} \mathrm{C}$ ) of smoldering corn stalk powder [40] and corn flour [6]. Supplement experiments show this temperature is always around $60{ }^{\circ} \mathrm{C}$ in natural piled rice husk. In our experiments of smoldering branches, there is even no obvious plat temperature at the preheating period, which is similar to smoldering of unwashed rice husk. It implies temperature in the fuel bed at drying stage might be related to the porosity inside the fuel bed, materials, particle size, air flow, etc. The detailed analysis of this will be left for future work. At the oxidation stage, the temperature first increases rapidly and then increases at a stable rate. It drops quickly at the end stage of oxidation. For both cases the highest temperatures are around $560.0^{\circ} \mathrm{C}$, being much lower than those in most combustors $\left(>700{ }^{\circ} \mathrm{C}\right)[41,42]$. The low temperature is favorable to maintain the amorphous state of the silica [43]. 

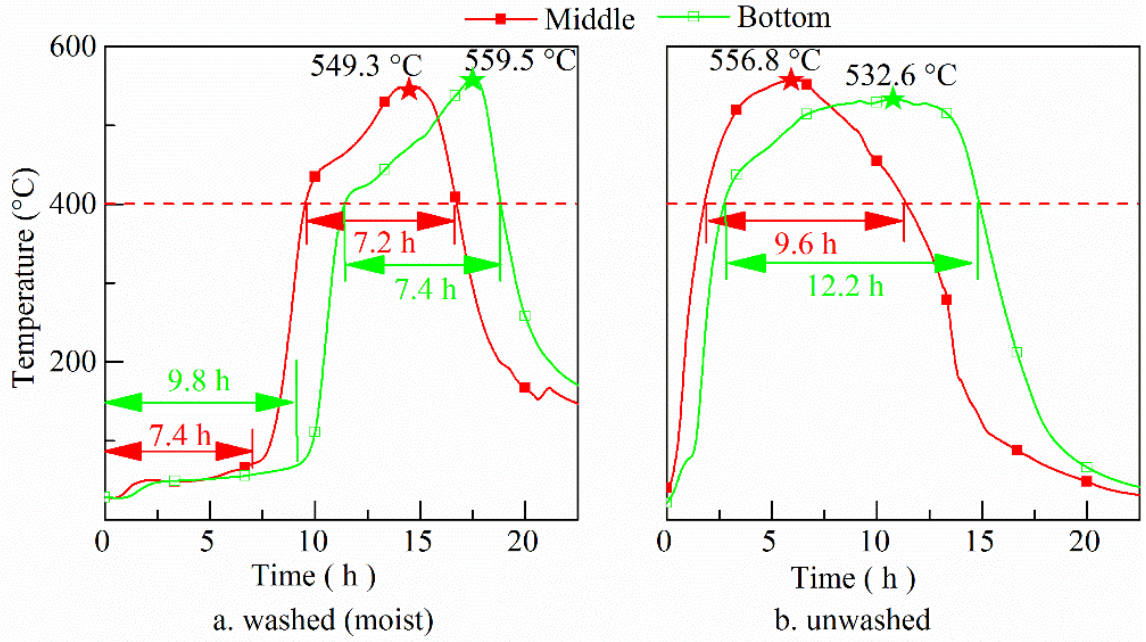

Figure 2. History of temperature of middle and bottom layer of washed (a) and unwashed (b) fuel bed (red and green pentacles for the maximum temperatures of middle and bottom layers, respectively).

Comparing the temperature development of the washed (moist) fuel bed with the unwashed fuel bed, the former has a longer duration of drying stage. The lower the part of the zone in the fuel bed, the longer the drying stage lasts. At oxidation stage, the duration of temperature $>400{ }^{\circ} \mathrm{C}$ of the moist fuel bed is shorter than for the unwashed fuel bed. This happens due to more heat generated in the process of smoldering is used to dry the moist rice husk and heat transfer rate to dry fuel is bigger than those for unwashed rice husk. The oxidation duration is also affected by bulk density of the fuel bed. In our supplementary experiments, smoldering of unwashed rice husk with bulk density of $170 \mathrm{~kg} / \mathrm{m}^{3}$ was performed in a small apparatus. It was found that the maximum temperature becomes higher (around $600^{\circ} \mathrm{C}$ ) than for naturally piled rice husk. The bigger bulk density decreases the porosity inside the fuel bed, reducing thermal dispersions [39]. Besides, another possible reason is that the dwell time of gaseous species is extended resulting in longer duration.

\subsubsection{Absorption of Volatiles by the Upper Ash}

A one-dimensional simplified illustration on temperature field of the whole fuel bed after formation of a thin layer of ash at top surface is shown in Figure 3. It was drawn according to the history of temperature inside the fuel bed, our previous experiments [40] and the characteristic temperature profile in a forward smoldering system in the literature [4]. Due to the longer drying time of the moist fuel bed than an unwashed one shown in Figure 2, the former has a thinner layer of high temperature area (reaction zone) than the latter after a short time, as illustrated in the curve of Figure 3. The amount of the unreacted rice husk (without pyrolysis) is proportional to the marked area of the left side. During their devolatilization, part of the volatiles can be absorbed by the upper ash due to its low temperature. As a result, the ash of the moist fuel bed has a higher tendency to absorb volatiles from its lower part than the ash of fuel with less moisture. 

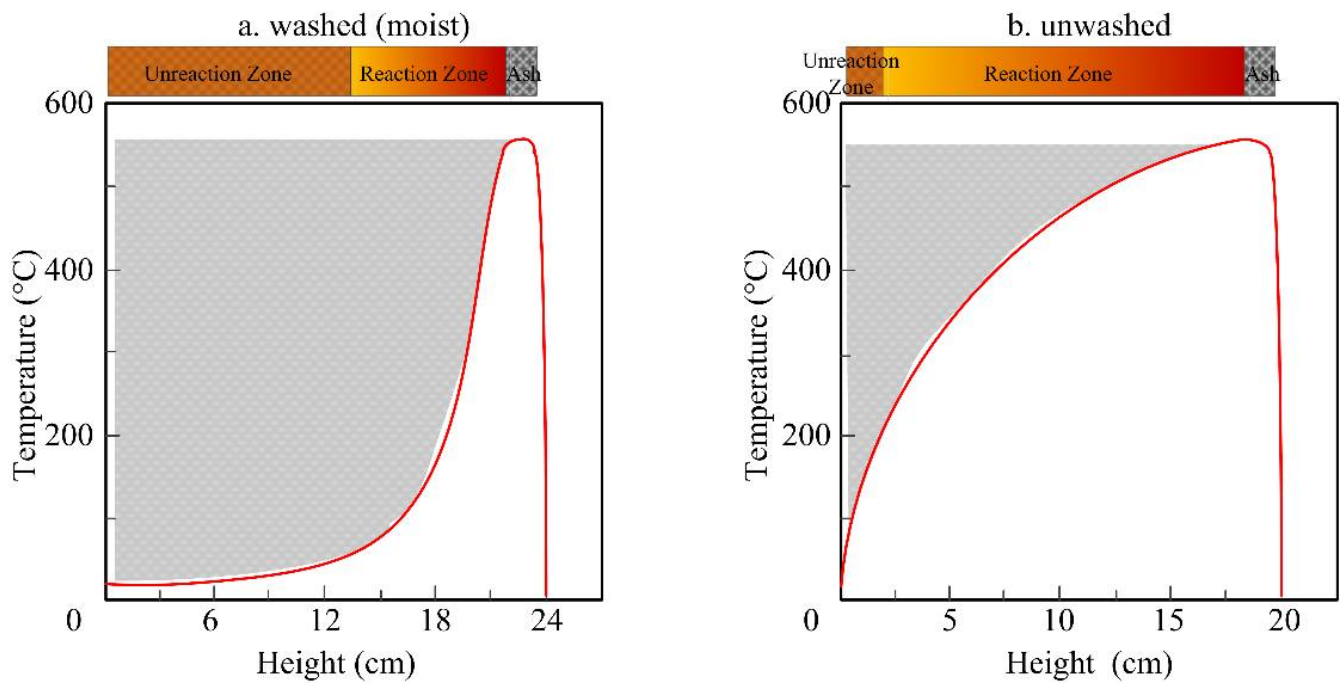

Figure 3. Schematic of spatial temperature distributions of washed (a) and unwashed (b) fuel bed.

3.2. Physical Properties and Mass Loss Characteristic of Rice Husk Ash

\subsubsection{Physical Properties of Ash}

Photos of ash before and after grinding from washed and unwashed smoldering as well as washed and unwashed burning are shown in Figure 4. These ashes are gray, soft, and almost retains the shape of rice husk itself. The whitest ash stems from washed burning, followed by unwashed burning. As for the other two ashes, the difference in the whiteness is negligible. The main reason is that temperature in smoldering $\left(560{ }^{\circ} \mathrm{C}\right)$ is significantly lower than in muffle furnace $\left(600^{\circ} \mathrm{C}\right)$ and the duration of this temperature in smoldering is shorter. Other possible reasons are the removal of impurities like dust by washing or absorption of volatiles by the upper ash. The higher the whiteness, the higher silica content in ash [44]. It is worth mentioning that there are always some black particles in the ash. These might be the rice husk with incomplete combustion. Bridge forming in the fuel bed that makes the cooling of the related particle faster than the dense piled should be the reason.
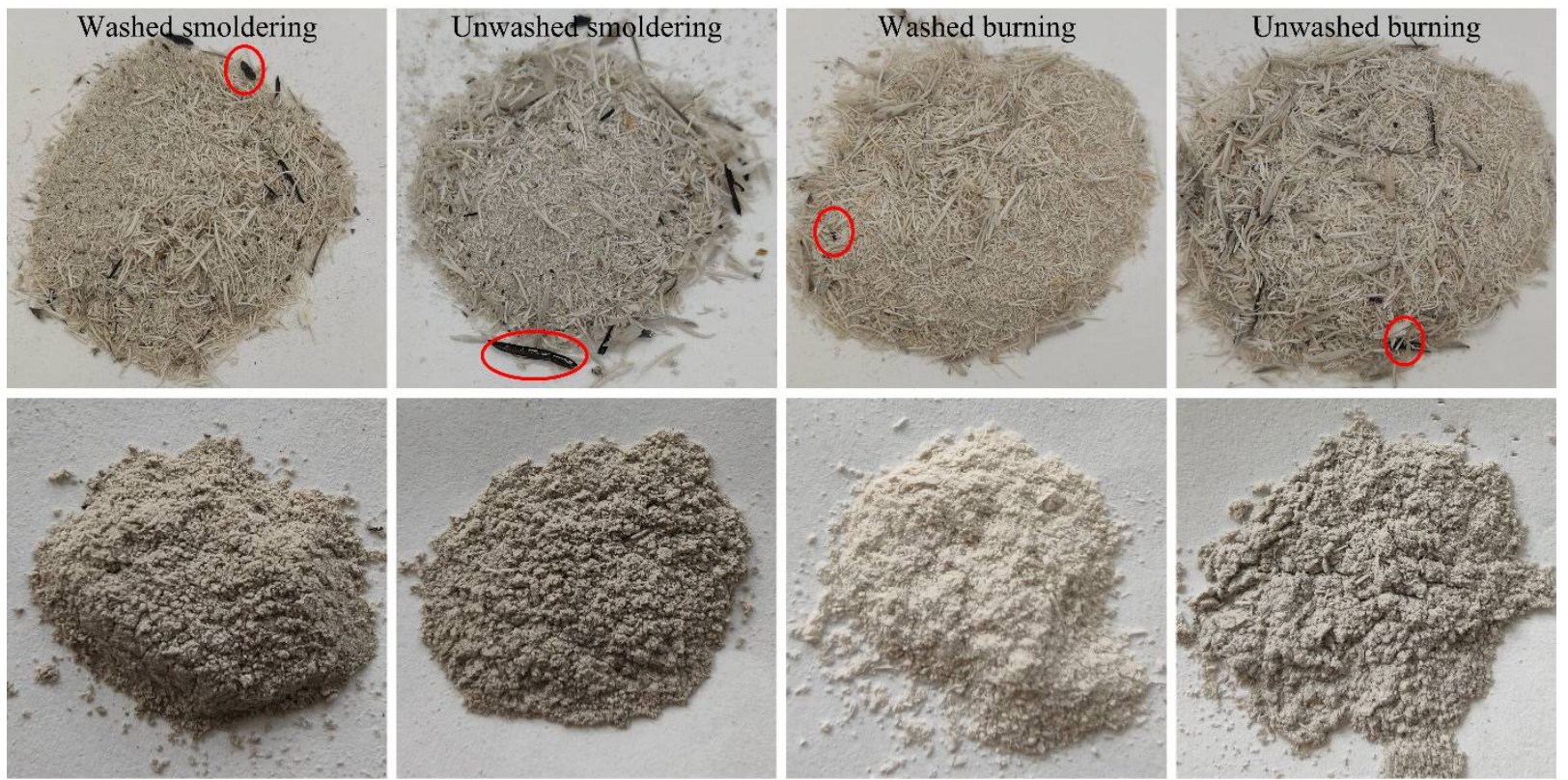

Figure 4. Photos of four types of rice husk ash (circles show black particles in ash). 


\subsubsection{Mass Loss Characteristic of Rice Husk Ash}

Thermogravimetric (TG) and derivative thermogravimetric (DTG) curves of four types of ash (washed and unwashed smoldering, washed and unwashed burning) are shown in Figure 5. It is seen from TG data that total mass-loss of four ashes is $<5 \%$. The mass loss from 50 to $950{ }^{\circ} \mathrm{C}$ for the above four types of ash are $4.2 \mathrm{wt} . \%, 3.1 \mathrm{wt} . \%, 2.5 \mathrm{wt} \%$, and $2.3 \mathrm{wt} . \%$, respectively. The lower the combustion temperature and oxidation duration, the higher total mass loss.

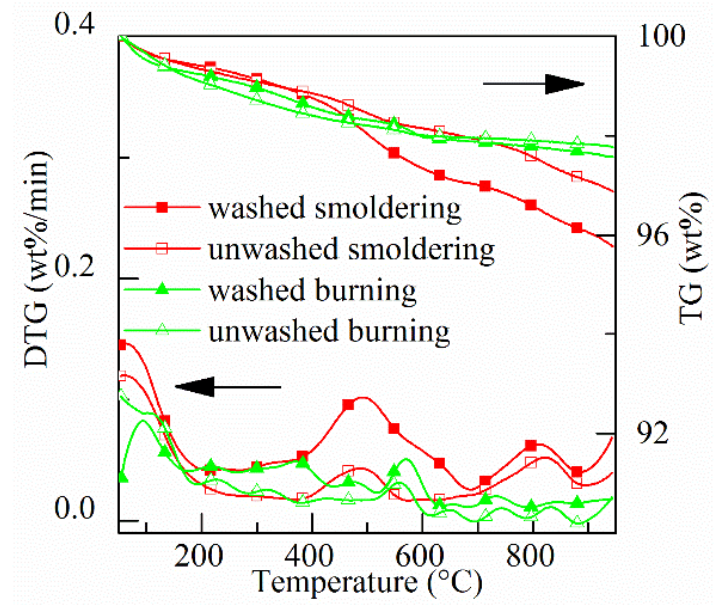

Figure 5. TG \& DTG curves of four types of ash.

As shown in the DTG curves, there are three stages of mass loss: drying, oxidation, and combustion of residual carbon. Mass loss at each stage is shown in Table 2. At the drying stage $\left(<200^{\circ} \mathrm{C}\right)$, more water and longer drying time are there for burning ash than those for smoldering ash. This implies that the absorption of condensed materials stated in Section 3.1.2 decreases the capability of moisture absorption of ash. At the oxidation stage $\left(200-700{ }^{\circ} \mathrm{C}\right)$, more mass is lost at lower temperatures for the two smoldering ashes than those for the burning ashes. For smoldering ashes, especially for smoldering of moist rice husk, mass loss occurs in the range $400-560{ }^{\circ} \mathrm{C}$. In theory, the mass in this range is burned out during smoldering due to the maximum temperature inside the fuel bed is around $560{ }^{\circ} \mathrm{C}$. The mass loss in this range indicates the oxidation of volatiles and carbon. At the stage of combustion of residual carbon $\left(>700^{\circ} \mathrm{C}\right)$, the mass loss of ash from smoldering is higher compared with burning ash due to more carbon in ash. The reason for the formation of residual carbon is that the melted silica obstructs the transport of oxygen to carbon [45]. At a higher temperature, the residual carbon can be burned out. Besides, the mass loss at this stage might also relate to the evaporation of $\mathrm{KCl}$ [38], the decomposition of carbonates [42].

Table 2. Mass loss of different stages (wt.\%).

\begin{tabular}{cccc}
\hline & Drying & Oxidation & Combustion of Resdiual Carbon \\
\hline Washed smoldering & $0.6 \pm 0.1$ & $2.4 \pm 0.2$ & $1.2 \pm 0.1$ \\
Unwashed smoldering & $0.7 \pm 0.1$ & $1.4 \pm 0.1$ & $1.0 \pm 0.1$ \\
Washed burning & $0.9 \pm 0.1$ & $1.3 \pm 0.1$ & $0.3 \pm 0.1$ \\
Unwashed burning & $0.8 \pm 0.2$ & $1.3 \pm 0.1$ & $0.2 \pm 0.1$ \\
\hline
\end{tabular}

\subsection{Silica Content in Rice Husk Ash}

\subsubsection{Reproducibility and Reliability of XRF Measurement}

Main compositions $(>0.5 \%$ ) from triplicate XRF measurements of ash produced by smoldering of washed rice husk are shown in Table 3. It is seen that the reproducibility is good (relative error $<10 \%$ ). As to reliability, if there are elements with atomic weights $<23$, 
the absolute contents of element are not reliable as pointed in Section 2.4. For smoldering ash, residue carbon and absorbed volatiles affect this measured elemental content.

Table 3. Contents of main elements in ash from triplicate measurements (wt.\%).

\begin{tabular}{|c|c|c|c|c|c|c|c|c|c|}
\hline NO. & $\mathrm{SiO}_{2}$ & $\mathrm{~K}_{2} \mathrm{O}$ & $\mathrm{CaO}$ & $\mathrm{SO}_{3}$ & $\mathbf{P}_{2} \mathrm{O}_{5}$ & $\mathrm{MgO}$ & $\mathrm{Cl}$ & $\mathrm{Fe}_{2} \mathrm{O}_{3}$ & $\mathrm{Al}_{2} \mathrm{O}_{3}$ \\
\hline 1 & 86.6 & 4.16 & 2.61 & 1.25 & 1.15 & 1.08 & 0.78 & 0.73 & 0.72 \\
\hline 2 & 86.4 & 4.20 & 2.70 & 1.26 & 1.23 & 1.14 & 0.81 & 0.71 & 0.70 \\
\hline 3 & 86.2 & 4.20 & 2.76 & 1.26 & 1.22 & 1.15 & 0.90 & 0.70 & 0.69 \\
\hline Ave & $86.4 \pm 0.20$ & $4.19 \pm 0.03$ & $2.69 \pm 0.08$ & $1.26 \pm 0.01$ & $1.20 \pm 0.05$ & $1.12 \pm 0.04$ & $0.83 \pm 0.07$ & $0.71 \pm 0.02$ & $0.70 \pm 0.02$ \\
\hline
\end{tabular}

\subsubsection{Content of Silica and Other Main Compositions in Rice Husk Ash}

The contents of $\mathrm{SiO}_{2}$ and others main compositions in the four types of ash are listed in Table 4. The main component is $\mathrm{SiO}_{2}$ and the contents of it in all ashes is $>85 \%$. The $\mathrm{SiO}_{2}$ content in descending order is washed burning (93.4\%), unwashed burning $(90.2 \%)$, unwashed smoldering $(89.0 \%)$, and washed smoldering (86.4\%). Contents of other compositions in descending order of the content are $\mathrm{K}_{2} \mathrm{O}, \mathrm{CaO}, \mathrm{SO}_{3}, \mathrm{P}_{2} \mathrm{O}_{5}, \mathrm{MgO}, \mathrm{Cl}, \mathrm{Fe}_{2} \mathrm{O}_{3}$, $\mathrm{Al}_{2} \mathrm{O}_{3}$ in smoldering ash, and this order holds for most elements in other ashes.

Table 4. Main compositions in 4 types of ash.

\begin{tabular}{|c|c|c|c|c|c|c|c|c|c|}
\hline Types & $\mathrm{SiO}_{2}$ & $\mathrm{~K}_{2} \mathrm{O}$ & $\mathrm{CaO}$ & $\mathrm{SO}_{3}$ & $\mathrm{P}_{2} \mathrm{O}_{5}$ & MgO & $\mathrm{Cl}$ & $\mathrm{Fe}_{2} \mathrm{O}_{3}$ & $\mathrm{Al}_{2} \mathrm{O}_{3}$ \\
\hline Washed smoldering & 86.4 & 4.19 & 2.69 & 1.26 & 1.20 & 1.12 & 0.83 & 0.71 & 0.70 \\
\hline Unwashed smoldering & 89.0 & 4.46 & 1.34 & 0.75 & 1.17 & 0.91 & 0.75 & 0.49 & 0.41 \\
\hline Washed burning & 93.4 & 1.07 & 2.08 & 0.58 & 0.50 & 0.70 & 0.30 & 0.39 & 0.21 \\
\hline Unwashed burning & 90.2 & 4.12 & 1.22 & 0.82 & 0.94 & 0.83 & 0.61 & 0.36 & 0.19 \\
\hline
\end{tabular}

\subsubsection{Effect of Production Method on Silica Content}

The purity of silica in ash is affected by three main factors: absorption of volatiles by upper ash, combustion temperature and pretreatment of rice husk. Volatiles adhering to the surface of upper-ash smoldering decreases the $\mathrm{SiO}_{2}$ content. Incomplete burn out of solid organics at low combustion temperature also decreases $\mathrm{SiO}_{2}$ content in ash. The pretreatment way of washing can remove some water soluble inorganics, such as $\mathrm{K}, \mathrm{Cl}$ and dust [46,47]. The removal of water soluble inorganics can increase the silica content [35]. According to Table 4, the measured silica content in ash of washed smoldering is similar to or lower than that in unwashed smoldering, while the content of water-soluble ions (Ca, $\mathrm{S}, \mathrm{P}, \mathrm{Mg}, \mathrm{Cl}, \mathrm{Fe}, \mathrm{Al}$ ) is higher than that in unwashed smoldering. The lower silica content for washed smoldering is related to the shorter oxidation duration in the moist fuel bed, which results in incomplete combustion of rice husk. The higher content of water-soluble ions might relate to the inaccuracy of XRF measurement as mentioned in Section 3.3.1. The removing of carbon results in an increase of those water-soluble ions contents as a percentage of the whole ash.

\subsection{BET Specific Surface Area}

\subsubsection{Specific Surface Area of the Four Types of Rice Husk Ash}

The BET specific surface area of ash produced in this study (washed and unwashed smoldering, washed and unwashed burning) and in literature is shown from Figure 6. Two characteristics can be seen from this data of this study: (1) The specific surface area of ash prepared from washed rice husk is higher than that from unwashed rice husk; (2) for the ash of prepared from washed rice husk, the specific surface area is lower when smoldering is used compared with burning in the muffle furnace. However, the situation is opposite for the ash prepared from unwashed rice husk. 


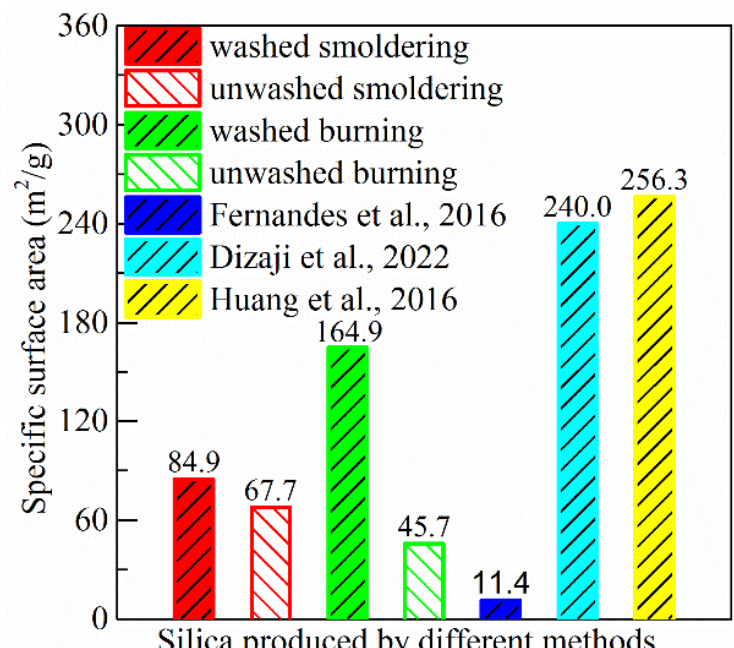

Figure 6. Specific surface area of silica produced by different methods. ([32]: no-pretreatment rice husk burned in a fluidized bed combustor; [28]: washed rice husk $\left(50{ }^{\circ} \mathrm{C}\right.$ tap water for $2 \mathrm{~h}$ ) burned in a muffle furnace $\left(600{ }^{\circ} \mathrm{C}\right.$ for $\left.4 \mathrm{~h}\right)$; [48]: citric acid-leached rice husk $\left(1 \mathrm{wt} . \%\right.$ at $80^{\circ} \mathrm{C}$ for $\left.3 \mathrm{~h}\right)$ burned in a muffle furnace $\left(700^{\circ} \mathrm{C}\right.$ for $\left.\left.2 \mathrm{~h}\right)\right)$.

\subsubsection{Factors of Specific Surface Area}

It can be seen from the above characteristics that the specific surface area is affected by pretreatment conditions and combustion temperature. Pretreatment, such as washing, removes part of potassium. This decreases the formation of eutectic from interaction of $\mathrm{K}$ and $\mathrm{Si}$. The decrease in amount of the eutectic partly avoids the transformation from amorphous silica to crystalline via melting in eutectic and condensing in cooling stage, and consequently increases the specific surface area [49]. Pretreatment of washing also removes soil particles which normally have lower specific surface area than amorphous silica.

As to temperature, low temperature avoids sintering/eutectic melting of the mixed components in ash of rice husk and is beneficial for silica to maintain its amorphous state and high specific surface area [50]. There is a combination effect of the two factors. It is very hard to get high-specific-surface-area ash from burning original rice husk at a high temperature $\left(>700^{\circ} \mathrm{C}\right)$.

3.4.3. Comparison of Specific Surface Area in This Study with Those of Silica Prepared Using Methods in Literature

The specific surface area of ash produced by smoldering of washed rice husk is $84.9 \mathrm{~m}^{2} / \mathrm{g}$, which is lower than those prepared in the laboratory $\left(99.2-293.9 \mathrm{~m}^{2} / \mathrm{g}\right)[13,29,51]$, but higher than those produced in the industry $\left(11.4-39.3 \mathrm{~m}^{2} / \mathrm{g}\right)[32,52]$, as shown in Figure 6. In the laboratory, rice husk is normally washed or leached using water and acid to remove alkali and alkaline earth metals, such as the experiments performed by Dizaji [28] and Huang [48]. In the industry, no-pretreatment rice husk is burned directly in combustors. The high temperature $\left(>700^{\circ} \mathrm{C}\right)$ of most combustor is not suitable to produce silica with high specific surface area.

\subsection{Supplementary Experiment of Smoldering Air-Dried Rice Husk after Washing}

To decrease the absorption of volatiles by upper ash, a supplementary smoldering experiment using air dried rice husk after washing was performed in the experimental set-up. It was found that the silica content is $93.5 \%$, and specific surface area is $145.9 \mathrm{~m}^{2} / \mathrm{g}$. Both the purity and specific surface are significantly higher than those $\left(86.4 \%, 84.9 \mathrm{~m}^{2} / \mathrm{g}\right)$ from moist rice husk. It shows that drying before smoldering does increase both silica content and specific surface area. 


\section{Potential of Mass Product of Silica from Smoldering of Rice Husk}

\subsection{Measures to Increase Silica Content and Specific Surface Area}

As mentioned before, the purity and specific surface area of silica produced from smoldering of rice husk are affected by pretreatment of the raw material, the volatile absorption of ash in reactor, and the solid temperature and dwell time in the fuel bed. According to the above experience in smoldering, two measures are proposed here to improve silica properties. The first is to develop a lateral continuously smoldering involving a dry stage apparatus. The second is to supply a little amount of air to improve fuel bed temperature slightly.

\subsubsection{Lateral Continuously Smoldering Involving a Dry Stage of Rice Husk}

A continuously lateral propagation smoldering is proposed here as shown in Figure 7. The smoldering of rice husk can be divided into three stages using a grate: drying, pyrolysis and oxidation. Due to its lateral propagation, the volatiles generated in the pyrolysis stage are discharged into the gas burning chamber directly and burned out, which cannot adhere to the ash in oxidation stage. The heat generated by oxidation can be used for the drying of rice husk. The condensate water generated in the process of drying can be collected and used for the washing of rice husk.

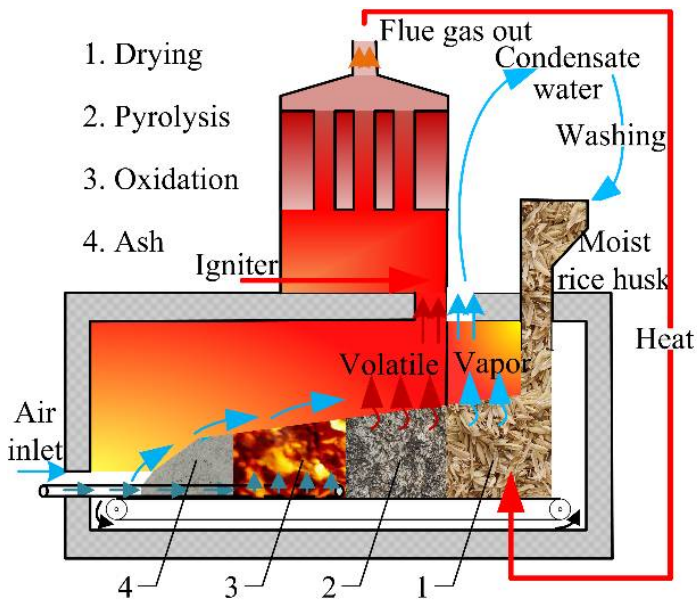

Figure 7. Schematic diagram of lateral continuously smoldering.

\subsubsection{The Supply of Air at the Oxidation Stage}

To increase the combustion temperature, a small amount of air can be provided in the stage of oxidation. As mentioned before, temperature of $700{ }^{\circ} \mathrm{C}$ can increase the purity and specific surface area. The highest temperature of the current piled smoldering is around $600^{\circ} \mathrm{C}$, which can be increased by supplying a small amount of air.

\subsection{Feasibility of Mass Product of Silica from Smoldering of Rice Husk}

Although silica prepared in the laboratory from pretreated rice husk has a high silica content and high specific surface area, considerable energy is necessary for removal of the water from moist rice husk. Besides, a lot of waste acid and lye is produced during pretreatment and post-treatment, which is harmful to the environment. As to a traditional combustor, the high temperature of the solid during combustion is disadvantageous in maintaining a high specific surface area of silica. Besides, most combustors are not suitable for burning rice husk with high moisture content.

Smoldering is characterized by a low temperature in the fuel bed and is self-sustained with moist content. Our experiments show that the highest silica content and specific surface area of ash is from smoldering of air-dried-washed rice husk. It indicates that after some improvement of our experimental set-up, it has great potential in the mass production of high-quality silica directly from moist rice husk. 


\section{Conclusions}

Smoldering experiments with moist rice husk were performed in a self-designed apparatus to check its possibility for silica production. Temperature inside the fuel bed and silica content/specific surface area/mass-loss-characteristics of ash were analyzed. The main conclusions are:

1. Smoldering is a novel method for producing silica from rice husk. In our experimental set-up with a smoldering chamber, a gas burning chamber and a heat exchanger, the smoldering was self-sustained for naturally-piled rice husk with moisture content of $51.0 \%$. Incomplete-combustion smoldering gas can be burned out in a gas burning chamber, and the heat generated during smoldering can be used for heating.

2. The highest temperature inside the fuel bed is around $560^{\circ} \mathrm{C}$, which was lower than those in many combustors. In the piled smoldering process of rice husk, part of the volatiles will be absorbed by the upper ash, which can decrease the silica content and specific surface area of ash. It should be avoided in the future.

3. Specific surface area of ash prepared from washed (moist) rice husk by smoldering was lower than those prepared in the laboratory, but it is higher than those produced from most industrial methods. It was greatly improved by air drying of moist rice husk before smoldering.

4. In future, a lateral continuously smoldering scheme involving a drying stage and small amount of air supply can be used for silica production. Smoldering of rice husk shows great potential for the industrial production of high-quality silica.

Author Contributions: Conceptualization, F.H.; methodology, F.H. and J.C.; software, S.Y. and F.H.; investigation, T.S.; data curation, T.S.; writing-original draft preparation, T.S.; writing-review and editing, D.Y., F.H., J.C., T.S. and F.B.; supervision, F.H.; funding acquisition, F.H. and F.B. All authors have read and agreed to the published version of the manuscript.

Funding: This research was funded by [National Natural Science Foundation of China] grant number [51676115] and [Sino-German Center for Research Promotion] grant number [M-0183].

Institutional Review Board Statement: Exclude this statement.

Informed Consent Statement: Not applicable.

Data Availability Statement: Data are available upon request.

Conflicts of Interest: The authors declare no conflict of interest.

\section{References}

1. Torero, J.L.; Gerhard, J.I.; Martins, M.F.; Zanoni, M.A.B.; Rashwan, T.L.; Brown, J.K. Processes defining smouldering combustion: Integrated review and synthesis. Prog. Energy Combust. Sci. 2020, 81, 100869. [CrossRef]

2. Lin, S.; Chow, T.H.; Huang, X. Smoldering propagation and blow-off on consolidated fuel under external airflow. Combust. Flame 2021, 234, 111685. [CrossRef]

3. Zhao, C.; Li, Y.; Gan, Z.; Nie, M. Method of smoldering combustion for refinery oil sludge treatment. J. Hazard. Mater. 2021, 409, 124995. [CrossRef] [PubMed]

4. Rashwan, T.L.; Fournie, T.; Torero, J.L.; Grant, G.P.; Gerhard, J.I. Scaling up self-sustained smouldering of sewage sludge for waste-to-energy. Waste Manag. 2021, 135, 298-308. [CrossRef]

5. $\quad$ Rashwan, T.L.; Torero, J.L.; Gerhard, J.I. The improved energy efficiency of applied smouldering systems with increasing scale. Int. J. Heat Mass Transf. 2021, 177, 121548. [CrossRef]

6. Rosa, A.; Hammad, A.W.A.; Qualharini, E.; Vazquez, E.; Haddad, A. Smoldering fire propagation in corn grain: An experimental study. Results Eng. 2020, 7, 100151. [CrossRef]

7. Wyn, H.K.; Konarova, M.; Beltramini, J.; Perkins, G.; Yermán, L. Self-sustaining smouldering combustion of waste: A review on applications, key parameters and potential resource recovery. Fuel Process. Technol. 2020, 205, 106425. [CrossRef]

8. Mitchell, E.J.S.; Gudka, B.; Whittaker, C.; Shield, I.; Price-Allison, A.; Maxwell, D.; Jones, J.M.; Williams, A. The use of agricultural residues, wood briquettes and logs for small-scale domestic heating. Fuel Process. Technol. 2020, 210, 106552. [CrossRef]

9. Stávková, J.; Maroušek, J. Novel sorbent shows promising financial results on P recovery from sludge water. Chemosphere 2021, 276, 130097. [CrossRef]

10. Feng, C.; Huang, J.; Yang, C.; Li, C.; Luo, X.; Gao, X.; Qiao, Y. Smouldering combustion of sewage sludge: Volumetric scale-up, product characterization, and economic analysis. Fuel 2021, 305, 121485. [CrossRef] 
11. Silva, L.A.; Santos, I.F.S.d.; Machado, G.d.O.; Tiago Filho, G.L.; Barros, R.M. Rice husk energy production in Brazil: An economic and energy extensive analysis. J. Clean. Prod. 2021, 290, 125188. [CrossRef]

12. Quispe, I.; Navia, R.; Kahhat, R. Energy potential from rice husk through direct combustion and fast pyrolysis: A review. Waste Manag. 2017, 59, 200-210. [CrossRef] [PubMed]

13. Santana Costa, J.A.; Paranhos, C.M. Systematic evaluation of amorphous silica production from rice husk ashes. J. Clean. Prod. 2018, 192, 688-697. [CrossRef]

14. Azat, S.; Korobeinyk, A.V.; Moustakas, K.; Inglezakis, V.J. Sustainable production of pure silica from rice husk waste in Kazakhstan. J. Clean. Prod. 2019, 217, 352-359. [CrossRef]

15. Zhang, H.; Ding, X.; Chen, X.; Ma, Y.; Wang, Z.; Zhao, X. A new method of utilizing rice husk: Consecutively preparing D-xylose, organosolv lignin, ethanol and amorphous superfine silica. J. Hazard. Mater. 2015, 291, 65-73. [CrossRef]

16. Luu, L.Q.; Halog, A. Rice Husk Based Bioelectricity vs. Coal-fired Electricity: Life Cycle Sustainability Assessment Case Study in Vietnam. Procedia CIRP 2016, 40, 73-78. [CrossRef]

17. Téllez, J.F.; Silva, M.P.; Simister, R.; Gomez, L.D.; Fuertes, V.C.; De Paoli, J.M.; Moyano, E.L. Fast pyrolysis of rice husk under vacuum conditions to produce levoglucosan. J. Anal. Appl. Pyrolysis 2021, 156, 105105. [CrossRef]

18. Siddika, A.; Mamun, M.A.A.; Alyousef, R.; Mohammadhosseini, H. State-of-the-art-review on rice husk ash: A supplementary cementitious material in concrete. J. King Saud Univ.-Eng. Sci. 2020, 33, 294-307. [CrossRef]

19. Adam, F.; Appaturi, J.N.; Iqbal, A. The utilization of rice husk silica as a catalyst: Review and recent progress. Catal. Today 2012, 190, 2-14. [CrossRef]

20. Ma, M.; Li, H.; Xiong, Y.; Dong, F. Rational design, synthesis, and application of silica/graphene-based nanocomposite: A review Mater. Des. 2021, 198, 109367. [CrossRef]

21. Lei, Q.; Guo, J.; Noureddine, A.; Wang, A.; Wuttke, S.; Brinker, C.J.; Zhu, W. Sol-Gel-Based Advanced Porous Silica Materials for Biomedical Applications. Adv. Funct. Mater. 2020, 30, 1909539. [CrossRef]

22. Soltani, N.; Bahrami, A.; Pech-Canul, M.I.; González, L.A. Review on the physicochemical treatments of rice husk for production of advanced materials. Chem. Eng. J. 2015, 264, 899-935. [CrossRef]

23. Goodman, B.A. Utilization of waste straw and husks from rice production: A review. J. Bioresour. Bioprod. $2020,5,143-162$. [CrossRef]

24. Beidaghy Dizaji, H.; Zeng, T.; Hartmann, I.; Enke, D.; Schliermann, T.; Lenz, V.; Bidabadi, M. Generation of High Quality Biogenic Silica by Combustion of Rice Husk and Rice Straw Combined with Pre- and Post-Treatment Strategies-A Review. Appl. Sci. 2019, 9, 1083. [CrossRef]

25. Tchakouté, H.K.; Rüscher, C.H.; Kong, S.; Ranjbar, N. Synthesis of sodium waterglass from white rice husk ash as an activator to produce metakaolin-based geopolymer cements. J. Build. Eng. 2016, 6, 252-261. [CrossRef]

26. Pfeiffer, T.; Enke, D.; Roth, R.; Roggendorf, H. Hydrothermal Dissolution of Opal in Sodium Hydroxide Lyes for the Synthesis of Water Glass. Adv. Chem. Eng. Sci. 2017, 7, 76-90. [CrossRef]

27. Schneider, D.; Wassersleben, S.; Weiß, M.; Denecke, R.; Stark, A.; Enke, D. A Generalized Procedure for the Production of High-Grade, Porous Biogenic Silica. Waste Biomass Valorization 2018, 11, 1-15. [CrossRef]

28. Beidaghy Dizaji, H.; Zeng, T.; Hölzig, H.; Bauer, J.; Klöß, G.; Enke, D. Ash transformation mechanism during combustion of rice husk and rice straw. Fuel 2022, 307, 121768. [CrossRef]

29. Bakar, R.A.; Yahya, R.; Gan, S.N. Production of High Purity Amorphous Silica from Rice Husk. Procedia Chem. 2016, 19, 189-195. [CrossRef]

30. Almeida, S.R.; Elicker, C.; Vieira, B.M.; Cabral, T.H.; Silva, A.F.; Sanches Filho, P.J.; Raubach, C.W.; Hartwig, C.A.; Mesko, M.F.; Moreira, M.L.; et al. Black $\mathrm{SiO}_{2}$ nanoparticles obtained by pyrolysis of rice husk. Dye. Pigment. 2019, 164, 272-278. [CrossRef]

31. Schliermann, T.; Hartmann, I.; Dizaji, H.B.; Zeng, T.; Schneider, D.; Wassersleben, S.; Enke, D.; Jobst, T.; Lange, A.; Roelofs, F.; et al. High quality biogenic silica from combined energetic and material utilization of agricultural residues. In Proceedings of the 7th International Symposium of Energy from Biomass and Waste, Venice, Italy, 15-18 October 2018.

32. Fernandes, I.J.; Calheiro, D.; Kieling, A.G.; Moraes, C.A.M.; Rocha, T.L.A.C.; Brehm, F.A.; Modolo, R.C.E. Characterization of rice husk ash produced using different biomass combustion techniques for energy. Fuel 2016, 165, 351-359. [CrossRef]

33. Aprianti, E.; Shafigh, P.; Bahri, S.; Farahani, J.N. Supplementary cementitious materials origin from agricultural wastes-A review. Constr. Build. Mater. 2015, 74, 176-187. [CrossRef]

34. Fernandes, I.J.; Calheiro, D.; Sánchez, F.A.L.; Camacho, A.L.D.; Rocha, T.L.A.d.C.; Moraes, C.A.M.; Sousa, V.C.d. Characterization of Silica Produced from Rice Husk Ash: Comparison of Purification and Processing Methods. Mater. Res. 2017, 20, 512-518. [CrossRef]

35. Pa, F.C.; Kein, W.K. Removal of iron in rice husk via oxalic acid leaching process. IOP Conf. Ser. Mater. Sci. Eng. 2019, 701, 012021 [CrossRef]

36. Kuprianov, V.I.; Kaewklum, R.; Sirisomboon, K.; Arromdee, P.; Chakritthakul, S. Combustion and emission characteristics of a swirling fluidized-bed combustor burning moisturized rice husk. Appl. Energy 2010, 87, 2899-2906. [CrossRef]

37. Werther, J.; Saenger, M.; Hartge, E.-U.; Ogada, T.; Siagi, Z. Combustion of agricultural residues. Prog. Energy Combust. Sci. 2000, 26, 1-27. [CrossRef]

38. Li, X.; He, F.; Behrendt, F.; Gao, Z.; Shi, J.; Li, C. Inhibition of $\mathrm{K}_{2} \mathrm{SO}_{4}$ on evaporation of $\mathrm{KCl}$ in combustion of herbaceous biomass. Fuel 2021, 289, 119754. [CrossRef] 
39. Gianfelice, G.; Della Zassa, M.; Biasin, A.; Canu, P. Onset and propagation of smouldering in pine bark controlled by addition of inert solids. Renew. Energy 2019, 132, 596-614. [CrossRef]

40. He, F.; Yi, W.; Li, Y.; Zha, J.; Luo, B. Effects of fuel properties on the natural downward smoldering of piled biomass powder: Experimental investigation. Biomass Bioenergy 2014, 67, 288-296. [CrossRef]

41. Faé Gomes, G.M.; Philipssen, C.; Bard, E.K.; Zen, L.D.; de Souza, G. Rice husk bubbling fluidized bed combustion for amorphous silica synthesis. J. Environ. Chem. Eng. 2016, 4, 2278-2290. [CrossRef]

42. Modolo, R.C.E.; Silva, T.; Senff, L.; Tarelho, L.A.C.; Labrincha, J.A.; Ferreira, V.M.; Silva, L. Bottom ash from biomass combustion in BFB and its use in adhesive-mortars. Fuel Process. Technol. 2015, 129, 192-202. [CrossRef]

43. Mlonka-Mędrala, A.; Magdziarz, A.; Gajek, M.; Nowińska, K.; Nowak, W. Alkali metals association in biomass and their impact on ash melting behaviour. Fuel 2020, 261, 116421. [CrossRef]

44. Gu, S.; Zhou, J.; Yu, C.; Luo, Z.; Wang, Q.; Shi, Z. A novel two-staged thermal synthesis method of generating nanosilica from rice husk via pre-pyrolysis combined with calcination. Ind. Crops Prod. 2015, 65, 1-6. [CrossRef]

45. Krishnarao, R.V.; Subrahmanyam, J.; Kumar, T.J. Studies on the formation of black particles in rice husk silica ash. J. Eur. Ceram. Soc. 2001, 21, 99-104. [CrossRef]

46. Bandara, Y.W.; Gamage, P.; Gunarathne, D.S. Hot water washing of rice husk for ash removal: The effect of washing temperature, washing time and particle size. Renew. Energy 2020, 153, 646-652. [CrossRef]

47. He, F.; Li, X.; Behrendt, F.; Schliermann, T.; Shi, J.; Liu, Y. Critical changes of inorganics during combustion of herbaceous biomass displayed in its water soluble fractions. Fuel Process. Technol. 2020, 198, 106231. [CrossRef]

48. Huang, M.; Cao, J.; Meng, X.; Liu, Y.; Ke, W.; Wang, J.; Sun, L. Preparation of $\mathrm{SiO}_{2}$ nanowires from rice husks by hydrothermal method and the RNA purification performance. Chem. Phys. Lett. 2016, 662, 42-46. [CrossRef]

49. Mirmohamadsadeghi, S.; Karimi, K. Recovery of silica from rice straw and husk. In Current Developments in Biotechnology and Bioengineering; Elsevier: Amsterdam, The Netherlands, 2020; pp. 411-433. [CrossRef]

50. Prasara-A, J.; Gheewala, S.H. Sustainable utilization of rice husk ash from power plants: A review. J. Clean. Prod. 2017, 167, 1020-1028. [CrossRef]

51. Lee, J.H.; Kwon, J.H.; Lee, J.-W.; Lee, H.-S.; Chang, J.H.; Sang, B.-I. Preparation of high purity silica originated from rice husks by chemically removing metallic impurities. J. Ind. Eng. Chem. 2017, 50, 79-85. [CrossRef]

52. Blissett, R.; Sommerville, R.; Rowson, N.; Jones, J.; Laughlin, B. Valorisation of rice husks using a TORBED ${ }^{\circledR}$ combustion process. Fuel Process. Technol. 2017, 159, 247-255. [CrossRef] 